\title{
Beobachtungen des Cometen I. 1870 auf der Sternwarte zu Athen.
}

Die Entdeckung des ${ }^{*}$ Cometen erfuhr ich spät durch eine Zeitung, so dass ich ihn nicht früher als Juni 16 sehen, und erst Juni 19 mit den Beobachtungeo beginnen konnte. Am 12. Juli gegen 15 Uhr suchte ich ihn (bei Vollmondlicht) vergebens. Ich würde ibn sicher noch beobachtet haben, wenn die Ephemeride den Ort des Cometen eine Woche weiter vorausberechnet hätte. $\mathrm{Da}$ der Meridiankreis zur Umarbeitung nach Wien geschickt ward, war ich genöthigt, mit dem Sextanten von Troughton Sonnen- und Sternhöhen zu nehmen, und zwar seit Juni 20. Diese Beobachtungen lieferten sehr gute Resultate; da aber ein starkes Erdbeben am 24. Juni die untere Uhr zum Stillstande brachte, und den Gang der Uhr in der Kuppesl störte, so kann ich die Zeit der Cometenbeobachtung an 19. Juni nicht auf einige Secunden verbürgen.

\begin{tabular}{|c|c|c|c|c|c|c|c|c|}
\hline Juni & 19 & $13^{\prime}$ & $51^{\prime}$ & $16^{5} 0$ & $\alpha+232^{s} 664$ & $\alpha-12^{\prime}$ & $45^{\prime \prime} 88$ & $\dot{4}$ \\
\hline$=$ & 25 & 14 & 7 & 5,0 & $\beta+51,185$ & $\beta+8$ & 34,39 & 4 \\
\hline$=$ & 25 & 14 & 24 & 41,3 & $\gamma-58,015$ & $\boldsymbol{\gamma}$ & & 4 \\
\hline$=$ & 29 & 14 & 26 & 6,6 & $\delta-27,140$ & $\delta-14$ & 53,76 & 5 \\
\hline Juli & 2 & 14 & 18 & 4,5 & $-13,449$ & $\varepsilon-0$ & 42,40 & 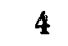 \\
\hline$=$ & 2 & 15 & 7 & 38,0 & $\varepsilon-5,615$ & $\varepsilon$ & - & 4 \\
\hline$=$ & 6 & 14 & 29 & 13,3 & $\zeta+190,700$ & $?-1$ & 35,96 & 4 \\
\hline$=$ & 7 & 14 & 24 & 56,0 & $\eta-39,699$ & $\eta+11$ & 55,77 & 4 \\
\hline$=$ & 9 & 14 & 40 & 11,5 & $-10,623$ & $6-2$ & 13,72 & 4 \\
\hline$=$ & 9 & 14 & 48 & 7,9 & $9+98,482$ & $9+14$ & 28,25 & 4 \\
\hline
\end{tabular}

Oerter des Cometen.

Juni $1913^{\mathrm{h}} 51^{\mathrm{m}} 16^{\mathrm{s}} 0, \alpha=1^{\mathrm{h}} 19^{\mathrm{m}} 14^{\mathrm{s}} 98, d=+21^{\circ} 11^{\prime} 28^{\prime \prime} 1$

$=251475,0 \quad 13246,86 \quad+164223,1$

$=291426 \cdot 6,6 \quad 14432,64 \quad+12321,3$

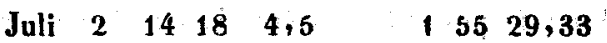

$+82620,8$

$=215738,0 \quad 15537,16 \quad+823$

$=6142913,3 \quad 21427,12$

$+1656,6$

7142456,0

22011,66

$-1812,5$

$=9144011,5$

23328,11

$-61623,0$

$=91448 \quad 7,9$

23330,16

$-61731,5$

Scheinbare 0erter der Vergleichsterne.

Anmerk. Alle benutzten Sterne sind einfach mittelst der Präcession auf 1870, und sodann mit den Angaben des Naut. Alman. auf den scheinbaren Ort reducirt. Sie entbehren sonach aller kleinen Correctionen, die entweder ihnen oder dea Cometenörtern noch beigefügt werden müssen.

$\alpha=$ Weisse $293,294 \quad 1^{\mathrm{h}} 15^{\mathrm{m}} 22^{\mathrm{s}} 32+21^{\circ} 24^{\prime} 14^{\prime \prime} 0$

$\beta=$ Weisse 702

$13155,68+163348,7$

$\gamma=$ B. D. 1855

$13255+1643$

$\delta=$ Weisse 786

1. $4459,78+124655,1$

$\varepsilon=$ Schjell. 598

$15542,78+82713,2$

Der Stern auch bei Bessel; doch habe ich nur Schjellerup's Ort benutzt.

$\zeta=$ Weisse 147, Schjell. $66121116,42+1832,5$ Hier nahm ich das Mittel aus Beiden, und berücksichtigte die eigene Bewegung nach Schjellerup.

$\eta=$ Weisse 324

$22051,36-1208,3$

$\iota=$ Weisse 566

$23338,70-6149,3$

$s=$ Weisse 526

$23151,68-63159,7$

Der Comet war stark verdichtet, und gut zu beobachten; das Licht rein weiss, und der Kern stets am starken Oculare auflösbar; der Schweif kurz und breit. Durch je 3-5 Passagen fand ich $s$ und $r$, die Schweiflänge und den Scheitelradius der Coma, wie folgt, wobei zu bemerken, dass stets bei höchster Reinheit der Luft und in Abwesenheit des Mondes beobachtet ward.

Die Helligkeit der centralen Region war zuletzt $=8^{\mathrm{m}} 7$.

$\begin{array}{rrrrr}\text { Juni } 25 & 14^{\mathrm{m}} 7 . & s=4^{\prime} 0, \quad r=1^{\prime} 68, & r^{\prime}=1^{\prime} 54 \\ =29 & 14,6 & 5,2 & 1,93 & 1,54 \\ \text { Juli } 2 & 15,0 & 5,6 & 2,11 & 1,50 \\ =6 & 14,7 & 9,9 & 2,47 & 1,50 \\ =7 & 14,7 & 9,4 & 2,83 & 1,65 \\ =9 & 15,0 & 20 & 2,76 & 1,47\end{array}$

$r^{\prime}$ giebt, nach nur vorläufiger Reduction, den Scheitelradius $\boldsymbol{r}$ in der Entfernung 1. gesehen. Der wahre Halbmesser der Coma des Cometen war zur Zeit dieser Beobachtungen durchschnittlich $10 \frac{1}{2}$ mal grösser als der der Erde.

At the n, 1870 Juli $15 . \quad J . F . J u l i u s$ Schmidt. 